\title{
Modernidad y Psicología: una disyuntiva
} y una paradoja.

\author{
Modernity and Psychology: a dilemma and a
}

paradox.

\author{
Nelson Ledezma \\ Universidad Central de Venezuela \\ nledezma@fonacit.gov.ve
}

\begin{abstract}
Resumen
La psicología que hoy día se practica, con pocas excepciones, comparte un conjunto de nociones, que he llamado "Marco de Racionalidad"; propias de la época moderna que ha propiciado su desarrollo. Dicho marco es el sustento del pensamiento positivista en las ciencias, cuya aplicación al ámbito de la psicología como ciencia básica o social genera una disyuntiva y una paradoja que lo hacen insostenible. Por ello se propone un marco de racionalidad desde la postmodernidad y algunas reflexiones, las cuales se orientan a enriquecer la discusión para la construcción de nuevas orientaciones en la ciencia psicológica.
\end{abstract}

Palabras clave: Modernidad, Postmodernidad, Marco de Racionalidad, Psicología.

\section{Presentación}

En una de las "subdisciplinas" de la psicología, a saber la psicología social, se había venido presentando en las tres últimas décadas una crisis en torno a su desarrollo y aplicación, a tal punto que en los actuales momentos la psicología social que se enseña y se practica avanza por nuevos caminos teóricos que la separan de aquella "psicología" en la cual tuvo sus comienzos, e incluso, la "nueva" psicología social ya no puede ser considerada como una "subdisciplina" de la psicología (o de la sociología, según sea el caso) sino como una disciplina en sí misma, con su propios paradigmas, teorías y campos de aplicación (donde inclusive puede rivalizar con la psicología tradicional). Sin embargo, más allá de la psicología social, en otras áreas donde se hace y se aplica la psicología (ej. la clínica, el asesoramiento, la industria, el deporte, etc.) tal crisis no ha tenido efecto y si lo ha tenido ha sido muy poco. En dichas áreas la psicología que se practica, aún cuando se presenta en diferentes posiciones teóricas (psicoanalíticas, conductistas, cognitivistas, humanistas, etc.), posee un conjunto de nociones "metafísicas" (en el sentido de no ser comprobables) que han caracterizado a la cultura occidental, principalmente, en el transcurso de la época moderna o período histórico posterior a la edad media. 
Esas nociones "metafísicas" han sido el sustento filosófico de la psicología tradicional y de todas las disciplinas científicas y áreas del conocimiento que surgieron en la época moderna. Sin embargo, dichas nociones se han visto cuestionadas desde el siglo XX, siglo en el cual, al parecer, se inicia una nueva época de la historia humana: una época postmoderna. La nueva época, de cuyo surgimiento y consolidación somos protagonistas, requiere un discurso que la legitime como tal y unos "principios" que fundamenten la "lógica" de los conocimientos y saberes que en ella se generen y difundan. Este discurso legitimador de la nueva época ha de tener muchas fuentes que argumenten en su favor fuentes que acá no pretendo dilucidar- las cuales de seguro abarcarán las distintas áreas en que la acción humana ha tenido parte, desde la filosofía hasta la ciencia, desde la religión hasta las artes.

Una de tales fuentes posibles del discurso legitimador de la nueva época lo constituye, sin lugar a dudas, la psicología; no solo porque las acciones humanas (que generan las condiciones para que surja la nueva época) y el estudio mismo del ser humano constituye su esfera de interés sino, porque es una disciplina cuya "delimitación científica" aún no se ha consolidado y ya ha comenzado, desde la psicología social, a jugar un rol protagónico en la aceptación de las consecuencias que la nueva época traerá a la ciencia. Consecuencias que de momento apuntan a la construcción de un nuevo paradigma para la ciencia ${ }^{1}$. En efecto, el cuestionamiento de los supuestos o nociones "metafísicas" de la época moderna que permitieron el origen de las "ciencias" ya hoy consolidadas como tales (las ciencias naturales) debilita las bases de dichas ciencias, por lo que se requiere de unos nuevos "supuestos" o "nociones" que las legitimen y que sustenten a las disciplinas que no gozan, aún, del status de ser científicas.

En este sentido es que apunta el presente trabajo. Ante la necesidad de que la psicología (y no solo la psicología social) asuma a plenitud el compromiso de cuestionar los supuestos "filosóficos" que la sustentan y, en consecuencia, participe en la construcción de un nuevo marco de racionalidad científica que la legitime como ciencia (y que legitime lo que ha de ser entendido como "ciencia"), se presentan en este trabajo algunas consideraciones críticas en torno a la "racionalidad" moderna y la psicología, y a partir de esas consideraciones se esbozan las características que comienza a presentar la "racionalidad" postmoderna, señalando luego algunas implicaciones de esa racionalidad para la psicología. Finalmente, estas consideraciones no pasan de ser un "llamado" a la reflexión crítica en psicología y si las mismas consiguen -al menos- que alguien desee refutar lo que aquí se dice, me daré por satisfecho y habré alcanzado mi objetivo.

\section{La época moderna y su racionalidad.}

La época moderna y las nociones "metafísicas" (como dije en la sección anterior) que la caracterizan podemos comprenderla en dos dimensiones, tal como lo hace Tomás Ibáñez (1996): una dimensión sociológica y una discursiva. La primera dimensión nos permite ubicar a la modernidad como una época históricamente situada, "(...) que se inicia en torno al año 1500 -siglo XVI, finales del siglo XVen Europa" (Ibíd. Pág. 61). La segunda dimensión, la discursiva, es la que nos permite identificarla

${ }^{1}$ El trabajo de Miguel Martínez (1996a; 1996b) apunta en esta dirección de proponer nuevos fundamentos al saber científico contemporáneo, apoyándose en cinco principios: la tendencia universal al orden en los sistemas abiertos, la ontología sistémica, el conocimiento personal, la metacomunicación del lenguaje total y la complementariedad. En relación con la psicología social véase lo que propone Maritza Montero (1994) a partir del cuestionamiento a la psicología social dominante (la llamada Psicología Social Psicológica). 
como un modo de pensamiento que reside en la cultura o como un conjunto de nociones "metafísicas". Ese conjunto de nociones "metafísicas", que subyace a la actual psicología tradicional, dominante o moderna, para los fines de este trabajo lo caracterizaré siguiendo las ideas de Fernando Mires (1996) quien lo denomina "paradigma". Para este autor un paradigma es "(...) un modo de ver las cosas" (pág. 156) y tiene su origen en la relación mutua que se establece entre una comunidad científica y el entorno cultural en el cual dicha comunidad se desenvuelve. Tal como señala Mires, "hay una relación permanente entre cultura y producción de ideas" (Ibíd. Pág. 157); en consecuencia, la cultura es el medio en donde se producen las ideas que la comunidad científica "perfecciona" y sistematiza para que luego esas ideas reviertan su efecto en la cultura que las engendra. Esta concepción de paradigma es similar a la noción que Egon Guba (1990) nos presenta "(...) en su sentido más genérico o común: Un conjunto básico de creencias que guían la acción" (pág. 17). De ambas nociones podemos extraer que un paradigma es un marco de referencia para las ideas que determina las acciones, que se produce en la cultura y los principios que lo sustentan no son demostrables; el paradigma simplemente se asume, no se verifica, se acepta como un sistema de principios fundamentales.

Entendiendo, entonces, que la dimensión discursiva o "paradigma" de la época moderna (también conocido como paradigma moderno) es un sistema de principios fundamentales que es común a la ciencia y a la cultura de dicha época, podemos caracterizar ese marco de pensamiento -de acuerdo con Fernando Mires (Ibíd.)- con los ocho principios que siguen a continuación:

1. La Determinación: según el cual entre causa y efecto hay una relación maquinal y lineal que elimina la libertad de los hechos causados (no hay efecto sin causa ni causa sin efecto). EI carácter teleológico de este principio es más evidente con la creencia en "causas indeterminadas" como origen último de las cosas y que no se pueden determinar.

2. El Naturalismo: es asumir que todo objeto que podamos conocer posee una naturaleza que lo define en armonía con la naturaleza del universo, es decir, que todo tiene un conjunto de propiedades características que ya están "dadas" al igual que el universo (que es anterior a nosotros). Esta idea de lo ya "dado", lo que ya existe, es la que expresamos cuando decimos que algo es "natural" y estudiar lo "natural" o la "naturaleza" es descubrir sus propiedades y su funcionamiento.

3. El Esencialismo: se asume que todo tiene una esencia que, obedeciendo a la relación causaefecto, determina su naturaleza (sus propiedades características). La esencia es lo que define a las cosas, es en sí la "causa" última, la naturaleza que debemos descubrir más allá de las apariencias, y para descubrir la esencia se debe dividir lo estudiado en sus partes constituyentes (es decir, "analizarlo").

4. El Racionalismo: el pensamiento racional (de acuerdo con la razón) es lo que nos acerca a la verdad, lo "irracional" (como la intuición o las emociones) solo nos aleja de ella. Al separar la naturaleza y la razón esta última se convierte en la instancia superior que define a la naturaleza y nos permite determinar la esencia de las cosas. Esto es lo que se ha denominado "el culto a la Diosa Razón".

5. El Pensar Dicotómico: es la lógica de lo mutuamente excluyente, lo que se opone, del todo o nada, de lo verdadero o falso. Es afirmar un hecho partiendo de la negación de otro que le es antagónico. Esto conduce a pensar que la naturaleza y todo lo conocible existen en dos formas: una real (que debemos descubrir) y una aparente (la que captan nuestros sentidos). 
6. La Proyección de Trascendencia: donde todas las acciones del presente están determinadas por un futuro ya establecido, un futuro que determina al presente y que es "superior" a este; dicho futuro se alcanza debido a que está "contenido" en las acciones del presente. Es este el principio que justifica la noción de "desarrollo" y la de "evolución": en ambas avanzamos hacia un estado superior, en el primero ese estado es el estado final predeterminado (desarrollarse es alcanzar un estado que ha estado latente) y en el segundo ese estado superior permite desplazar y superar al antecedente.

7. El Orden Universal: se asume que toda la naturaleza posee un orden que debe ser develado, de allí el interés en descifrar las leyes de la naturaleza; dichas leyes son los principios que determinan el orden del universo que se debe descubrir y son leyes universales y objetivas.

8. La diferencia entre lo Objetivo y lo Subjetivo: esto es, asumir que la naturaleza a la cual podemos acceder y debemos descubrir existe con independencia del observador, quien no afecta la manifestación de la misma. La naturaleza es un "objeto" externo, con leyes que la rigen, y cualquiera que distancie sus valores, preconcepciones y prejuicios -es decir, su subjetividad- puede "descubrirla".

Como puede notarse todos estos principios se complementan y pueden ser resumidos en dos grandes grupos: los principios ontológicos y los principios epistemológicos. Los ontológicos son aquellos que se refieren a "(...) la naturaleza de lo "conocible" (...) ó (...) de la "realidad" (...)" (Egon Guba, 1990: pág. 18), y los epistemológicos aluden a "(...) la naturaleza de la relación entre el conocedor (el investigador) y lo conocido (o conocible) (...)" (ídem.). En este sentido, la determinación, el naturalismo, el esencialismo, la proyección de trascendencia y la creencia en el orden universal son principios de carácter ontológico; $y$, si se quiere para los fines de este trabajo, podemos resumirlos en uno: "el esencialismo naturalista". A su vez el racionalismo, el pensar dicotómico y la diferenciación entre lo objetivo y lo subjetivo son principios epistemológicos; que podemos resumir en: "la dicotomía" (este también es "ontológico" en cuanto se aplique a la naturaleza de las cosas "conocibles").

Por otra parte, dichos principios están implícitos -a mi juicio- en tres de los cuatro "paradigmas" de la ciencia que Guba (Ibíd.) identifica: el positivismo, el postpositivismo y la teoría crítica (la excepción es el constructivismo). En el positivismo se evidencian en una ontología "realista", según la cual "(...) la realidad existe "allí afuera" y es manejada por leyes y mecanismos naturales inmutables" (Ibíd. Pág. 20) y una epistemología "dualista" y "objetivista" que señala que "(...) es tanto posible como esencial para el investigador adoptar una distancia, una postura no interactiva [con la realidad]" (Ídem.). En el postpositivismo se evidencian en una ontología "realista crítica" (se asume que la realidad que existe "allí afuera" no puede ser completamente aprehendida por las limitaciones humanas) y una epistemología "objetivista modificada" (se mantienen los principios del positivismo pero se considera la objetividad como un "ideal" a alcanzar que solo se obtiene en forma aproximada). En la teoría crítica los principios descritos se evidencian solamente en un nivel ontológico, ya que esta perspectiva asume un realismo crítico como en el postpositivismo pero en el nivel epistemológico se desliga del "paradigma" moderno. Por otra parte, el propio Guba (Ibíd.) identifica al postpositivismo y a la teoría crítica (junto con el constructivismo) como "paradigmas emergentes" (pág. 20) que han surgido como alternativas frente al "positivismo" dominante en las ciencias.

Lo dicho hasta ahora me conduce a pensar que el "paradigma" descrito por Fernando Mires (1996) es "un sistema de principios fundamentales" que antecede a los "paradigmas" que presenta Guba 
(1990). En tal sentido, en este trabajo voy a asumir una "jerarquía" entre ambas nociones, de manera que el "paradigma moderno" de Mires antecede y subyace a los tres "paradigmas" que Guba ha caracterizado. Por lo tanto, me tomaré la libertad de denominar en forma diferente a dichos "paradigmas": el "paradigma" de Mires lo llamaré "Marco de Racionalidad" y para los "paradigmas" de Guba tomaré prestado el término "Metaparadigma" que emplea Frederic Munné (1989) para designar a los modelos de ciencia (realmente creo que Guba habla de "modelos de ciencia", en el sentido de Munné, por lo que me parece apropiada tal equivalencia), reservando el término "paradigma" para designar -al igual que Munné- los diferentes modelos del hombre en las ciencias sociales. Así las cosas, al "paradigma moderno" lo entenderemos, de ahora en adelante, como "Marco de racionalidad Moderna" y la mejor expresión del mismo es el "Metaparadigma positivista" (o "paradigma positivista" según Guba).

\section{La modernidad en la psicología tradicional.}

El "Metaparadigma positivista" o "positivismo" sintetiza la filosofía adoptada por las ciencias naturales en su origen y consolidación y, además, fue el metaparadigma a seguir por toda aquella disciplina que quería alcanzar el status de "científica". Es por esta razón que las ciencias sociales (incluyendo la psicología) construyen sus cimientos teóricos sobre tales bases paradigmáticas; sin embargo, dicho metaparadigma presenta, al menos, una "limitación" importante al querer aplicarlo a este tipo de "ciencias": sus objetivos generan una disyuntiva éticamente no sustentable.

En este sentido los objetivos que se evidencian en el "metaparadigma positivista" son, de acuerdo a Egon Guba, "(...) predecir y controlar los fenómenos naturales" (Ibíd. Pág. 19). Además, no solo se persigue "predecir y controlar" se busca crear un conocimiento "imparcial", sin compromisos políticos o ideológicos, que sea aplicable universalmente trascendiendo las generaciones y las culturas (de allí la separación "sujeto-objeto", todo sujeto investigador esta inmerso en una cultura y un contexto social que, de no excluirse, invalida la "universalidad" del conocimiento producido). Estos objetivos hacen "válido" al metaparadigma positivista y han permitido que las ciencias naturales generen aplicaciones que han hecho posible el avance tecnológico de la actualidad y los grandes logros de la ciencia moderna (ej. el uso de la energía atómica, la comunicación satelital, los viajes espaciales, etc.).

En las ciencias sociales la aplicación de tales objetivos nos enfrenta a una disyuntiva que confronta y hace incompatibles los objetivos "modernistas": al conocer y comprender las realidades sociales ponemos al descubierto las prácticas que la sostienen y al tratar de "predecir y controlar" esas prácticas hacemos de las ciencias sociales unas disciplinas para manipular a los seres humanos; así, las mismas se convierten en instrumentos que pudiesen servir a intereses políticos e ideológicos particulares y no tendríamos entonces un conocimiento "imparcial" y sin compromisos ideológicos. Por ejemplo, en psicología si predecimos y controlamos la conducta de consumo este conocimiento puede ser utilizado por las empresas de mercadeo para "manipular" a los consumidores y hacerles comprar sus productos o, también, si predecimos y controlamos la intención de voto o la conducta de afiliación política, cualquier partido político puede emplear este conocimiento para "manipular" a los electores. En otras palabras, si predecimos y controlamos los hechos sociales por ser fieles a los objetivos "supremos" del metaparadigma positivista no podemos cumplir sus otros objetivos: crear un conocimiento "imparcial" sin compromisos ideológicos y que sea universalmente aplicable. 
Esta disyuntiva en las ciencias sociales al pretender cumplir los objetivos del positivismo me conduce a asumir que dicho metaparadigma no es aplicable en las disciplinas de estas ciencias, no obstante el lector pudiese preguntarse lo siguiente: ¿si el metaparadigma positivista no es aplicable en las ciencias sociales y requiere ser sustituido, no es posible desarrollar otros metaparadigmas al interior del marco de racionalidad moderna y conservar este último? Desde luego que sí, podemos desarrollar otros metaparadigmas rechazando o reformulando algunos principios de la racionalidad moderna (por ejemplo: el postpositivismo reformula la ontología y la epistemología del positivismo al asumir una versión "light" de los mismos en la ontología realista crítica y la epistemología objetivista modificada; y la teoría crítica rechaza la separación entre lo subjetivo y lo objetivo al asumir una epistemología subjetivista); no obstante, la disyuntiva presentada no se soluciona con la adopción de "nuevos" metaparadigmas modernos ya que los objetivos señalados se originan en el esencialismo naturalista y la dicotomía que caracterizan a la modernidad (no solo al positivismo) y que articulan sus principios característicos.

En efecto, el esencialismo naturalista y la dicotomía nos hacen asumir que todo fenómeno tiene "algo" (la esencia) que siempre ha existido (naturalismo) y que debe ser descubierto más allá de las apariencias (dicotomía esencia-apariencia). Ese "algo" sería lo que subyace a las apariencias de las cosas las cuales deben estar, de alguna manera, determinadas o causadas por su "esencia". Si tal "determinismo" es real, entonces, es posible determinar las leyes del "orden" subyacente a tal "esencia", por demás "trascendente". Y una vez determinadas las leyes de ese "orden" podemos "predecirlo" y "controlarlo". Si así concebimos los fenómenos de la realidad podemos entonces justificar una separación "dicotómica" entre lo "objetivo" (la "esencia" del fenómeno) y lo "subjetivo" (la "esencia" del investigador). Dicha separación (o "epistemología de la distancia" como la llama Pablo Fernández Christlieb, 1994) nos permite capturar la "esencia" de los fenómenos estudiados, incluyendo los individuos y la sociedad, con la exclusión de la "subjetividad" del investigador (lo cual derivaría en un conocimiento "imparcial") y con ellas elaborar un conocimiento que será más "válido" y "universal", por un lado, en la medida que mejor represente las "realidades" bajo estudio (esto último es lo que Ibáñez, 1996, denomina "ideología de la representación") y, por el otro, en la medida que mejor "controle y prediga" las "esencias" de dichas "realidades".

Como consecuencia de la crítica anterior podemos preguntarnos lo siguiente: ¿Si no son sostenibles los objetivos de la modernidad en las ciencias sociales cuales serían, entonces, sus objetivos fundamentales? En mi opinión, a esto podemos responder que los objetivos alternativos que se deben plantear para las ciencias sociales (asumiendo que la predicción y el control no son plausibles) son: 1) hacer inteligibles las relaciones y prácticas sociales que subyacen a las diferentes realidades humanas; y 2) enriquecer las dinámicas de producción de realidades sociales creando los espacios de discusión, los modelos de interpretación y/o producción y las realidades alternativas a las estudiadas. Este último objetivo es compatible con la propuesta que hace Fernández Christlieb (1987) para la psicología social, a la cual considera como "intrínsecamente" política en el sentido que tiene una función similar al proceso de "politización" que él define como "(...) comunicar lo incomunicable, en hacer que las experiencias que se vivencian como personales o privadas puedan ocupar un lugar en la esfera pública con el objeto de ser debatidas" (pág. 92). De esta manera se asume el compromiso de proponer pluralidades y no propuestas únicas, incrementar los significados que se manejan en la vida pública y sacar de la vida privada los significados que las "ideologías" dominantes prohíben o no toleran en la esfera pública. 
Ahora bien, por lo dicho hasta ahora podemos aceptar que las ciencias sociales deban rechazar el esencialismo naturalista y la dicotomía de la modernidad por los inconvenientes que acarean al estudiar la "realidad social"; no obstante, podemos no aceptar que la psicología sea una ciencia social y, por lo tanto, no rechazar esos principios. Diríamos, por ejemplo, -para justificar esa decisión- que la conducta, los procesos cognitivos o los procesos inconscientes no son "objetos" de una ciencia social ya que estos son individuales, no sociales y al estudiarlos entramos en el terreno de las ciencias naturales que estudian "objetos" ya dados en la naturaleza como los fenómenos psicológicos mencionados, los cuales existen en nosotros, nos definen, son nuestra "esencia" como humanos y no los hemos construidos en nuestras relaciones sociales; por el contrario, ellos nos permiten relacionarnos. Más aún: esos "objetos" o fenómenos psicológicos son tan "individuales" y "subjetivos" que nuestra propia experiencia lo confirma: tenemos sensaciones, percepciones, pensamientos, imaginaciones, sueños, entre otras cosas, las cuales experimentamos individualmente, sin la intervención de otros individuos.

Entonces, si hacemos la afirmación anterior ¿Qué podemos concluir? ¿Es la psicología una ciencia natural que se escapa de los comentarios y limitaciones que señalamos al marco de racionalidad moderna, o, es una ciencia social que debe aceptar esas críticas? Si concluimos que la psicología es una ciencia natural nos limitamos a estudiar "objetos" individuales y estaríamos fraccionando la unidad disciplinar de la psicología con sus áreas aplicadas -en tanto subdisciplinas que comparten unos intereses de estudio (objetos, fenómenos o procesos), métodos, técnicas o modelos teóricosya que se excluye, al menos, a la psicología social contemporánea que ha venido desarrollándose al margen de la psicología individual (como de hecho ha venido ocurriendo y así lo mencioné al comienzo de este trabajo) y a la psicología industrial u organizacional que también se ubica al margen de lo subjetivo. Si, por el contrario, optamos por concluir que la psicología es una ciencia social limitándonos a los "procesos sociales" estaríamos excluyendo justamente lo que nos ha dado origen como disciplina: lo subjetivo o lo individual; no obstante, en la psicología contemporánea ambas conclusiones parecen encontrarse. Así, no sería extraño que la neuropsicología, psiconeuroinmunología o el análisis experimental de la conducta se les pueda considerar como ciencias naturales y la psicología comunitaria, ambiental, política, organizacional o la psicología de las masas, como ciencias sociales (sobre la ubicación de la psicología en el marco de las ciencias naturales o sociales volveré en la sección dedicada a explorar las implicaciones que tendría para la psicología adoptar la postmodernidad).

Pese a esto, aunque fuésemos firmes defensores de quienes sostienen que la psicología es una ciencia natural, ocupada de fenómenos "individuales", no pudiésemos ocultar la necesidad de rechazar el esencialismo naturalista y la dicotomía como principios fundamentales de la racionalidad subyacente a la psicología; esto debido a que dichos principios generan una paradoja al interior de nuestra disciplina. La paradoja generada es que el psicólogo en su afán de objetividad cree acceder a la realidad psicológica "tal y como es" en el otro sin que medie su "subjetividad", no obstante, es su "subjetividad" y no otra cosa la que hace inteligible la realidad psicológica estudiada. En otras palabras, el psicólogo (el sujeto que conoce) procura conocer la "subjetividad" (la esencia) de otro (el objeto conocido) sin que intervenga su "subjetividad" que, al fin de cuentas, es la que quiere conocer la "subjetividad" del otro y es quien la interpreta; esto equivale a preguntar: ¿cómo puede un psicólogo distanciar su "esencia" de la "esencia" que estudia sin que ésta última sea distorsionada por la suya propia, es decir, cómo puede ser objetivo? No podemos acceder a la "subjetividad" de otro a no ser que empleemos la "subjetividad" nuestra, desde la pura "intuición" hasta el empleo de modelos teóricos complejos, aún cuando empleemos instrumentos de medición sofisticados (desde los tests 
hasta los equipos de laboratorio que emplean los analistas experimentales de la conducta), los mismos han llegado a existir como producto de una "subjetividad" (o varias) que le han dado forma. Es más, esta paradoja no es exclusiva de la psicología (entendida como ciencia natural) sino que la comparten todas las ciencias sociales: en estas, cuando la "esencia" de lo que se estudia (las interacciones sociales o los productos de ellas) no es diferente (dicotómico) de la "esencia" del proceso de investigación (interacciones sociales: sujeto-objeto) se vuelve insostenible tal modelo al interior de las ciencias sociales, esto debido a que la "esencia" de la investigación incide en la "esencia" de lo estudiado de la cual no es diferente (ambas son interacciones y productos sociales).

¿Cómo es que el esencialismo naturalista y la dicotomía producen esta paradoja? En principio, y tal como puede inferirse al mencionar la paradoja, la misma se debe al ideal de "objetividad" de la modernidad en la cual se conjugan los dos mencionados principios (la "dicotomía" sujeto-objeto distancia al sujeto del objeto para poder acceder a la "esencia natural" del mismo). No obstante, es posible señalar la incidencia de cada principio, por separado, en la existencia de esa paradoja. El esencialismo naturalista, al postular la existencia de "esencias" ya dadas naturalmente en los objetos estudiados, fija la base para que consideremos al ser humano provisto de una esencia que nos permita entenderlo (llámese: psique, mente, cognición, conducta, o similares); por lo tanto, el objetivo es acceder a dicha esencia y teorizar sobre ella para hacer inteligible al ser humano. La dicotomía, a su vez, nos obliga a asumir la necesidad de distanciar nuestra "subjetividad" (como expresión de nuestra "esencia") de la "subjetividad" estudiada, de manera que, podamos elaborar un conocimiento de ella que sea libre de la influencia de nuestra "subjetividad"; es decir, un conocimiento objetivo.

De estas consideraciones si hay una conclusión adecuada (independientemente de que asumamos la psicología como ciencia social o natural) esta es la que ya se había señalado con anterioridad: es plausible rechazar el esencialismo y la dicotomía como principios fundamentales de la racionalidad subyacente a nuestra disciplina. No obstante, rechazar dichos principios implica sustituir el marco de racionalidad moderna que ellos configuran y que ellos sintetizan; en consecuencia, en la sección que sigue voy a tratar de delinear algunos "principios" para la época postmoderna que nos permitan sustituir el marco de racionalidad que hasta aquí he estado cuestionado (la modernidad).

\section{Hacia un marco de racionalidad postmoderna.}

Tratar de delimitar un "marco de racionalidad" para la época "postmoderna" en la cual estamos inmersos no es tarea sencilla pero un buen punto de partida, al menos para la psicología, lo constituye asumir que el mismo debe superar las limitaciones que, en la sección anterior, le atribuí al esencialismo naturalista y la dicotomía de la modernidad; así mismo es importante recordar que los marcos de racionalidad surgen en la cultura y no en la ciencia (aunque se formalicen en ella) por lo tanto el marco de racionalidad que acá pretendo caracterizar no es exclusivo de la ciencia (o la psicología) sino que, al igual que su homólogo moderno, es común a la ciencia y a la cultura que lo origina. En este sentido, la cultura occidental ha venido profundizando en un proceso que estuvo presente en el origen del marco de racionalidad moderna y comprender dicho proceso es importante para poder romper con el esencialismo y la dicotomía de la modernidad. Se trata de "un proceso de secularización" -como lo denomina Ibáñez (1996: pág. 67)- el cual consiste en despojar del carácter religioso y trascendente a los principios y valores que sustentan a una época o sociedad; es como dice Ibáñez "se les hace bajar de las trascendencias puesto que se sitúan en la propia humanidad y en la sociedad. Esto, significa la muerte metafórica de Dios" (Ídem.). Dicho proceso, en el marco de la 
época moderna, no logró desligar la racionalidad moderna del "Marco de racionalidad Religiosa" que le antecedió ya que procedió con una lógica de sustituir la figura de Dios por otros "absolutos" (la razón, la ciencia, la naturaleza, etc.) que produjeron los mismos efectos; es así como el "culto a Dios" da lugar al "culto a la Razón" y la "salvación" y la "verdad" que la religión ofrecía se sustituye por el "progreso" y la "verdad" del conocimiento científico. De manera que el esencialismo naturalista y la dicotomía de la modernidad se derivan de la racionalidad religiosa, en esta última la esencia de la naturaleza es su dimensión "espiritual" (y la esencia natural humana es su "alma") y la dicotomía opone a dicha "esencia" una dimensión "material" (en el ser humano el "cuerpo" se opone a su "alma").

Entendida entonces la modernidad como un proyecto de secularización no acabado (ya que la lógica de la "sustitución" no elimina lo religioso y lo trascendente) la postmodernidad se erige como la culminación de dicho proyecto. De allí que Fernando Mires (1996) hable de una "segunda secularización" al referirse a la revolución paradigmática que está dando lugar a la postmodernidad; en este sentido el nuevo "marco de racionalidad" se opone al carácter religioso de la modernidad. Es por esta razón que Mires (Ibíd) señala que "todo paradigma [entiéndase: "Marco de Racionalidad"] surge como oposición a otro" (pág. 159). En consecuencia, si el marco de racionalidad moderno surgió en oposición al de racionalidad religiosa, podemos decir entonces que el "Marco de Racionalidad Postmoderna" surgiría oponiéndose al que le antecede. Pero, a diferencia de la "modernidad" que opuso al marco de racionalidad religioso otros "absolutos" sin socavar sus "principios" (por el contrario, los adoptó), el marco de racionalidad postmoderna le opone a la modernidad (y a la religiosidad subyacente) otros "principios" que socavan y contradicen los principios de la modernidad al negar los "absolutos" que caracterizan a los marcos de racionalidad religiosa y moderna.

Siguiendo el pensamiento de Mires (Ibíd), entonces, la nueva "racionalidad" se caracterizaría por ser "todo lo contrario" a los elementos de la racionalidad moderna ya descritos, es decir, que sería: indeterminista, antinaturalista, antiesencialista, antirracionalista, antidicotómico, sin proyección de trascendencia, no asume un orden universal y no establece diferencia entre lo objetivo y lo subjetivo; además, la lógica que afirma a la postmodernidad solo se hace clara en la medida que se conozca el marco de racionalidad al cual se opone (es decir, la modernidad).

Por otra parte, si -como hace Ibáñez (1996)- entendemos la modernidad como una época o período histórico, también podemos entender -con este autor-que la postmodernidad sea una época que se inicia a mediados del siglo XX. Por lo tanto podemos tratar de identificar los factores que han hecho posible que de las prácticas sociales contemporáneas este emergiendo un "discurso" de la postmodernidad. En este sentido, la postmodernidad se haya inmersa en unas prácticas sociales cuya dinámica y complejidad van en un aumento vertiginoso, debido a lo que algunos han denominado "las tecnologías de la inteligencia" (Ibáñez, Ibíd. Pág. 62) las cuales posibilitan "(...) ciertas operaciones de pensamiento que no eran del todo posibles antes de que esas tecnologías de la inteligencia, se construyeran. (...), en definitiva, crear nuevas formas del pensar" (Ídem.); es así como la postmodernidad va a emerger en un momento histórico en el cual hace su aparición en escena una de estas "tecnologías de la inteligencia": "(...) el ordenador, quien va a propiciar su constitución" (Ibíd. Pág. 69).

En efecto, la invención del ordenador o computadora creó nuevas posibilidades de pensamiento, nuevos términos, nuevos significados, nuevos modos de producción económica, nuevas maneras de relación entre las personas; en fin, nuevas "realidades". Nuevas "realidades" como la interacción 
entre personas situadas en lugares distantes (la interacción no se limita a un encuentro "cara a cara"), la lectura no lineal de textos, la simulación de modelos de la "realidad", etc., todo en una carrera "contra reloj". La máxima parece ser: "hacer más en menos tiempo". Y hacer más en menos tiempo es "eficiencia" -producir los efectos deseados en menor tiempo- ya no es suficiente con producir los efectos deseados ("eficacia") hay una demanda de "inmediatez" cuya satisfacción es adecuarse a una "realidad" tan dinámica y cambiante que no podemos "aprehender" estáticamente.

La eficiencia que parece exigir el mundo postmoderno de la informática parece encaminarnos a pensar que lo "mejor" que podemos hacer para "aprehender" la realidad que nos rodea es plantearnos "modelos de la realidad" susceptibles de tales cambios, más allá de que representen adecuadamente la realidad lo que importaría es que los mismos capten la dinámica y el cambio de la realidad. Si esto se asume y se consolida en esos términos, entonces, la búsqueda de "modelos" que mejor nos permitan obtener resultados de una realidad dinámica se convertiría en un principio (que podemos llamar "optimización") característico de esta época y de esta racionalidad que llamamos "postmodernidad". Un ejemplo de la presencia de este "principio" lo vemos, a mi juicio, en la psicología social en quienes abogan por el estudio de las "producciones discursivas"; tales "producciones" son dinámicas, cambiantes, constantemente se producen y reproducen y no sería apropiado proponer un modelo de las mismas que las considere como estáticas, hay que ser "sensibles" a su dinámica social.

Entendida la postmodernidad como una época, entonces, podemos asumir que esta se inicia con la invención de la computadora a mediados del siglo XX; pero entendida en términos de un "modelo de racionalidad" no podemos fijar un comienzo a algo que está en construcción. Si seguimos a Ibáñez (Ibíd) también esta época presenta dos dimensiones: una sociológica y una discursiva. La dimensión sociológica nos permite entenderla como una época y ubicarla entonces en relación con algunos eventos históricos (de los cuales solo he mencionado la invención de la computadora) y la dimensión discursiva, o discurso que legitima dicha época, nos permite entenderla como un "marco de racionalidad".

En tanto marco de racionalidad (dimensión discursiva) podemos decir con Ibáñez (Ibíd) que la postmodernidad presenta dos dimensiones. "Primero, una dimensión crítica, de demolición, de desconstrucción del discurso de la modernidad. En este sentido la postmodernidad es una antimodernidad". (...) Segundo, una dimensión legitimadora de la nueva época, junto con una propuesta programática." (Pág. 71, énfasis en el original). La primera de estas dimensiones ya la señalé con Mires (1996) cuando dije que la postmodernidad se opone a la modernidad y que la lógica que afirma dicha racionalidad se hace clara cuando se conocen los principios de la racionalidad moderna. No obstante, no delimité en ese momento unos "principios" característicos debido a que esto corresponde a la "dimensión legitimadora" la cual, como dije antes, "esta en construcción". Es por ello que lbáñez señala que el discurso legitimador de la nueva época es "(...) confuso, (...) diverso, contradictorio, incoherente. (Ídem.). Sin embargo se atreve a mencionar algunos aspectos de dicho discurso, sin ahondar en detalles, cuando dice: "El discurso legitimador insiste sobre la fragmentación, la fragmentación de la realidad, la fragmentación del sujeto y sobre el relativismo en el campo de los conocimientos y de los valores" (Ibíd. Pág. 72).

Tratemos entonces de entender a que se refiere Ibáñez cuando habla de fragmentación y de relativismo. La fragmentación no debe ser entendida aquí como un sinónimo de "análisis" como se entiende en la modernidad (dividir el "todo" en sus partes constituyentes para identificar las "esencias"). Desde el marco de racionalidad moderna tanto la realidad (lo conocido) como el sujeto (el 
conocedor) son totalidades; para que la realidad estudiada sea "objetiva" debe ser "única", existir en una sola forma (tener una sola "esencia") de manera que cualquiera con el método adecuado pueda "descubrir" la porción de la realidad que investiga. A su vez, el sujeto que conoce esa realidad también es "único", es un sujeto que distancia su "subjetividad" y, por lo tanto, se convierte en un sujeto "común" a todo investigador o, empleando los términos de Jean Piaget (1979), el investigador procura un distanciamiento "(...) del sujeto individual en la dirección del sujeto epistémico" (Pág. 22). Ante estas concepciones se opone la postmodernidad. La fragmentación de ambas entidades (realidad y sujeto) es aceptar, por un lado, que la realidad no es "única" y que pueden existir múltiples "versiones" de la misma y, por el otro, la imposibilidad de que el investigador se convierta en el "sujeto" moderno.

A su vez, el relativismo que defiende Ibáñez (Ibíd) se desprende de la "fragmentación" y es el que subyace a esta afirmación suya: "la realidad es necesariamente de tipo convencional" (Pág. 81; negritas en el original); lo que tal afirmación supone es que la realidad no existe con independencia de las convenciones lingüísticas que utilizamos para referirnos a ella. En otros términos, "No hay un mundo que sea independiente de la versión a partir de la cual lo construimos" (Ibíd. Pág. 83) o, lo que es lo mismo, no podemos hacer referencia a la realidad sin emplear alguna forma de convención lingüística. En consecuencia, pueden existir tantas versiones de la realidad como "versiones" puedan ser elaboradas y aceptadas convencionalmente por los grupos sociales. Por lo tanto, si hay muchas "versiones" de la realidad, los conocimientos que de ellas se obtienen son relativos (dependen de su contexto de producción) y si el "sujeto" se fragmenta, es decir se acepta que cada investigador tiene un conjunto de prejuicios, valores, preconcepciones y elementos "subjetivos", personales, que median en su rol de investigador, entonces la investigación no puede gozar de valores únicos, estos serán relativos y estarán mediados por los del investigador.

A partir de las ideas anteriores, tanto de Fernando Mires (1996) como de Tomás Ibáñez (1996), voy ahora a proponer unos principios "característicos" del marco de racionalidad postmoderna que está emergiendo de la cultura y la ciencia actual. Estos principios no son en ninguna forma concluyentes sino, simplemente, una sugerencia para continuar la elaboración de este discurso legitimador de la nueva época; los mismos los voy a definir y denominar como sigue:

1. La complejidad: las cosas y los hechos que constituyen la "realidad" se interrelacionan de tal manera que son "interdependientes"; cualquier elemento de la misma es necesario para explicarla aunque no sea suficiente. Pueden haber tantas "causas" como elementos sean considerados en el estudio de un fenómeno. Esto implica que no hay "esencias" que definan "naturalezas", ni un "orden universal" sujeto a leyes causa-efecto (leyes causales) que "determinen" los hechos.

2. La optimización: es buscar la mejor manera de obtener algo, apostando a los resultados y no a los medios para conseguirlos, es decir, lo importante es obtener resultados útiles asumiendo que al conseguirlos los medios empleados se adecuan a la realidad. Esto conduce a proponer modelos dinámicos capaces de cambiar, no estáticos, que "funcionen" poco importa si representan la "realidad".

3. La fragmentación: es asumir que la realidad no es una sola y que hay "coexistencia" de múltiples "versiones" de la misma, ya que la realidad no existe con independencia de las convenciones lingüísticas que utilizamos para referirnos a ella; es decir, no podemos hacer referencia a la realidad sin emplear alguna forma de convención lingüística. En consecuencia, 
pueden existir tantas versiones de la realidad como "versiones" puedan ser elaboradas y aceptadas convencionalmente por los grupos sociales (esto también lo pudiese llamar: "relativismo ontológico" pero para diferenciarlo del "relativismo epistemológico" prefiero usar el término "fragmentación"). Esto niega el "naturalismo" (la realidad no está dada la construimos), el "esencialismo" y la "trascendencia" de la modernidad.

4. El relativismo: también pudiese llamarlo "relativismo epistemológico". Se asume que el conocimiento obtenido de la realidad esta ligado a las condiciones sociales e históricas que lo hicieron posible y a los individuos que los elaboran. El conocimiento no es "universal" y "trascendente" a las generaciones y culturas, ni más "verdadero" si "refleja" la realidad, por el contrario, solo será "verdadero" al interior de la sociedad que lo produce y entre quienes lo asuman como tal. Esto implica que es imposible alcanzar el "sujeto epistémico" que conoce la realidad al margen de su subjetividad.

5. El subjetivismo: el conocimiento que se obtiene de la realidad es un producto subjetivo de la capacidad intelectual de quienes lo elaboran, no es un "reflejo" de la realidad sino una versión constituyente de la misma; el conocimiento de la realidad y la realidad son la misma cosa: una elaboración humana. Este principio niega la separación entre lo objetivo y lo subjetivo.

Estos cinco principios que, a mi juicio identifican a la postmodernidad que esta emergiendo, los podemos -al igual que hicimos con los de la modernidad- agrupar en: ontológicos y epistemológicos resumiéndolos en dos principios que los articule a todos. Así, los principios ontológicos (que nos dicen como es la realidad) serían: la complejidad y la fragmentación, que lo resumimos en el primero: "la complejidad" y los principios epistemológicos (que nos dicen como es la relación sujeto-objeto que produce conocimiento) serían: la optimización, el relativismo y el subjetivismo, que podemos resumirlos en: "el relativismo".

Por otra parte, en relación con los "paradigmas" de la ciencia o "metaparadigmas" como he preferido llamarlos en este trabajo que Egon Guba (1990) ha descrito, los cinco principios anteriores de la postmodernidad creo que están presentes en el "constructivismo". En este sentido, dicho "metaparadigma" se caracteriza por asumir una ontología "Relativista" (como la define ese autor), según la cual "(...) las realidades existen en la forma de múltiples construcciones mentales, social y experiencialmente basadas, dependientes local y específicamente en sus formas y contenidos de las personas que las sostienen" (Ibíd. Pág. 27); lo cual le da cabida a lo que aquí he llamado "complejidad" y "fragmentación". A su vez, en el plano epistemológico el constructivismo es "subjetivista", es decir, que asume que "(...) el investigador y lo investigado están fusionados en una entidad única (monista). Los hallazgos son literalmente la creación de los procesos de interacción entre los dos" (Ídem); lo cual, en mi opinión, es compatible con lo que he llamado "optimización", "relativismo" y "subjetivismo". Veamos ahora, en la sección que sigue, algunas de las posibles implicaciones que tendría para la psicología adoptar los principios del modelo de racionalidad postmoderna. 


\section{Algunas implicaciones de la racionalidad postmoderna}

\section{para la psicología.}

Al rechazar el esencialismo naturalista y la dicotomía (de la modernidad) y asumir que, al menos, la complejidad y el relativismo (de la postmodernidad) han de sustentar la nueva racionalidad de la psicología, me veo en la obligación de "asomar" algunas de las posibles implicaciones que tendría para la psicología asumir el marco postmoderno tal como lo he descrito. No pretendo acá presentar una agenda completa para la "nueva" psicología, por el contrario, mi intención es "esbozar" las implicaciones que creo, en este momento, serían importantes para comenzar la reflexión en torno a los nuevos "metaparadigmas" y "paradigmas" que la ciencia y la psicología requieren. En consecuencia no debemos olvidar, para las reflexiones que tengan lugar a partir del marco que he esbozado, que la "postmodernidad" en tanto discurso legitimador está en "construcción", no es un producto acabado (a diferencia de la modernidad), por lo que -en principio- mucho de lo que aquí he dicho (y podamos decir) puede no ser en un futuro muy próximo; hecha esta aclaratoria me atrevo entonces a decir lo siguiente:

$>$ En primer lugar, y retomando una interrogante que había dejado en el aire: ¿Es la psicología una ciencia natural o una ciencia social? Podemos señalar desde la nueva racionalidad que al rechazar el esencialismo naturalista y la dicotomía la separación de las ciencias en ciencias naturales y ciencias sociales ("humanas" o "del espíritu", como también se les conoce) pierde vigencia; es bajo el pensamiento moderno que esa distinción tiene sentido ya que se asume que la naturaleza (objeto de las ciencias naturales) y la sociedad (objeto de las ciencias sociales) son "ontológicamente" diferentes, son dos dominios de la realidad independientes entre sí que no se influyen recíprocamente. Esto no es más que una concepción dicotómica de la realidad que la postmodernidad rechaza ${ }^{2}$. Desde la postmodernidad podemos decir que la naturaleza y la sociedad son similares (no iguales) "ontológicamente" en el sentido de que ambas son relativas (siguiendo al metaparadigma constructivista) a las construcciones o convenciones socialmente producidas para entenderlas. A ninguna le subyace una "esencia" ya dada (natural) que las defina y las separe sino que su naturaleza (propiedades y características) viene dada por los modelos teóricos y convenciones que utilicemos en su estudio y comprensión. Es decir que, en cierto sentido, la "naturaleza" y la "sociedad" son "sociales" en la medida en que lo que sabemos de ellas (y podemos saber) son un producto de la interacción entre individuos. Esto nos obligaría a reconceptualizar las ciencias "naturales" y "sociales" en otros términos que se escapan al propósito de estas reflexiones.

$>$ En segundo lugar, y derivado de lo anterior, así como lo "conocible" de la naturaleza y la sociedad son productos "sociales", los "objetos" psicológicos no son individuales, en el sentido de estar al margen de la interacción interindividual que, a mi entender, define lo "social". Esto debido a que la única manera en que podemos saber que los "objetos" psicológicos son individuales es que exista un conjunto de prácticas sociales que los asuma como tal, es decir, que un colectivo particular (llámese, grupo, sociedad o comunidad científica) en sus interacciones y relaciones sociales haya establecido qué cosa es lo

${ }^{2}$ Esta "dicotomía" de la realidad no niega la realidad única (no fragmentada) a la que se opone Ibáñez (1996). Para la modernidad cada ámbito de la realidad estudiada es "único" en el sentido de poseer una sola esencia que lo explica; así, la realidad natural y la realidad social tienen cada una su propia esencia que las hace "objetivas" al investigador. 
"individual" y que elementos se entienden como tales. En consecuencia, también son "sociales" en el mismo sentido de la "naturaleza" y la "sociedad". Aún cuando podemos decir que tales "objetos" psicológicos los experimentamos individualmente ("mi pensamiento es individual porque solo yo lo pienso") no debemos dejar de lado que tales "experiencias" las hacemos "conscientes" debido a que podemos emplear elementos del lenguaje, símbolos y palabras, cuyos "significados" son sociales. Esto no significa que dichos objetos, desde una perspectiva metodológica, no puedan ser abordados "individualmente" (centrados en un solo sujeto) sino que en la apropiación teórica de los mismos no se debe excluir su "naturaleza" social. ${ }^{3}$ De esta manera se asume el principio de la "complejidad" del modelo de racionalidad postmoderno.

> En tercer lugar, y derivado del anterior, si teóricamente admitimos la "naturaleza" social de los "objetos" psicológicos (independientemente de que algunos de ellos los abordemos en individuos aislados y otros, en colectividades) las distintas "subdisciplinas" de la psicología pueden converger bajo una perspectiva "metaparadigmática" (modelo de ciencia) y "paradigmática" (modelo de ser humano) común, que no defina "procesos", "mecanismos" y "realidades" psicológicas de carácter "universal" sino "fragmentados", es decir, propios de los contextos socio-histórico-culturales de los individuos y su particular inserción en los mismos. De esta manera se reconoce la "complejidad" del ser humano $y$, en consecuencia, su "fragmentación" en tanto realidad conocible. Esto requiere delimitar ese "metaparadigma"4 y ese "paradigma" al interior de la ciencia postmoderna y la psicología.

D En cuarto lugar, y como para rechazar lo anterior, el "nuevo" discurso de la ciencia y de la cultura de la época postmoderna se puede erigir como un discurso "totalizador" similar al de la modernidad; es decir, un discurso que no admita discrepancias y disidencia en su seno. Por lo tanto, la psicología en el reconocimiento de esa "complejidad" y ese "relativismo" postmoderno en un "paradigma" único para su disciplina puede obviar "explicaciones" alternativas no concebidas en su interior y, de esta manera, contradecir el "relativismo" y la "fragmentación" que debe defender; generando con ello una paradoja que debemos atender.

En síntesis, estas breves implicaciones que el discurso de la postmodernidad traen, a mi entender, a la psicología la podemos resumir en lo siguiente: la psicología fundamentada en la "fragmentación" y el "relativismo" de la postmodernidad requiere conceptualizar su objeto de estudio como un fenómeno "social" cuya naturaleza reside en las interacciones humanas, esto obliga a la psicología a rechazar sus modelos y teorías "intrapsíquicas" e "individualistas" para darle paso a modelos y teorías "fragmentados" o, como dije antes, «propios de los contextos socio-histórico-culturales» en los cuales surgen.

${ }^{3}$ Un buen ejemplo de esta tentativa de conceptualizar lo "individual" en términos "sociales" lo constituye -aunque no es explícitamente postmoderno- el trabajo del psicólogo cubano Fernando González Rey en torno a la personalidad y la subjetividad (véase: Fernando González Rey; 1994; 2002).

${ }^{4}$ Para los fines de este trabajo dicho "metaparadigma" es el constructivista que Guba (1990) describe, no obstante, como he asumido que el discurso legitimador de la postmodernidad está en "construcción" no descarto que otras alternativas puedan surgir y, en consecuencia, sean asumidas.

${ }^{5}$ En cuanto al "paradigma" de la psicología, en tanto modelo de ser humano y no de "escuela" teórica, creo que la postmodernidad nos apunta a considerar al ser humano como un agente constructor de su realidad (lo que hace, dice y piensa) por medio de sus interacciones con otros; aunque, tal como pienso del "metaparadigma", pueden asumirse otras concepciones más "complejas". 


\section{En conclusión.}

Para finalizar voy, en primer lugar, a realizar una síntesis de lo dicho en las páginas anteriores y, en segundo lugar, a puntualizar algunas ideas críticas en torno al modelo de racionalidad postmoderna y el lenguaje que utilizamos desde esta perspectiva metateórica.

En cuanto a la síntesis de las ideas expuestas tenemos: que el marco de racionalidad moderna se caracteriza, básicamente, por ser esencialista-natural y dicotómico, dos aspectos que articulan los diferentes principios de la modernidad y que derivan en dos objetivos básicos para la ciencia moderna: predecir y controlar lo estudiado. Estos dos objetivos generan una disyuntiva al interior del marco de racionalidad moderna al pretender aplicarlo en las ciencias sociales dado que contradicen a los otros objetivos de la modernidad: ¿cómo producir un conocimiento imparcial y aplicable universalmente?; esto debido a que la "realidad social" no es independiente del investigador. Por otra parte, al interior de la psicología la aplicación de este marco de racionalidad genera una importante paradoja: el psicólogo pretende obtener un conocimiento de la "subjetividad" de otra persona sin que intervenga su "subjetividad"; no obstante, es a partir de su "subjetividad" que conoce e interpreta la de otros. Ante tal disyuntiva y tal paradoja asomé la necesidad de descartar ese modelo de racionalidad para las ciencias sociales y la psicología, esbozando algunos principios característicos del modelo de racionalidad postmoderna que ha venido emergiendo actualmente. Dicho modelo de racionalidad lo he sintetizado en la "complejidad" y el "relativismo" los cuales articulan los principios de la postmodernidad emergente. Las implicaciones que esta racionalidad tiene para la psicología giran en torno al rechazo del "individualismo" tradicional.

Ahora bien, en cuanto a las ideas críticas sobre el modelo de racionalidad postmoderna y el lenguaje que utilizamos, quiero llamar la atención sobre dos cuestionamientos. El primer cuestionamiento es el siguiente: ¿de qué manera hablamos de la "naturaleza" de las cosas que estudiamos? Si cuando hablamos de la naturaleza de algo nos estamos refiriendo a como está constituido, que lo caracteriza, que lo define o como está dado para el investigador que lo estudia, entonces estamos hablando de una "esencia" de los fenómenos estudiados en el sentido que la modernidad asume el término "esencia" (algo ajeno a nuestra actividad humana, es decir, "natural"). Si, por el contrario, entendemos que la naturaleza de algo se refiere a como asumimos su constitución, que características le atribuimos, como lo definimos y como nos lo apropiamos, entonces estamos reconociendo que no accedemos a una "esencia" (en el sentido modernista) sino que elaboramos una "esencia" para hacer inteligible un fenómeno; es decir, reconocemos nuestra actividad humana como constructores de la realidad que estudiamos y conocemos.

El segundo cuestionamiento que quiero plantear es: ¿no dejamos entrever una ontología esencialista cuando empleamos el verbo "Ser" en nuestras descripciones? Dicho verbo (al menos en el idioma español) suele ser usado para referirnos a condiciones "absolutas" de las cosas que describimos o a las que hacemos referencia, así por ejemplo, cuando decimos "la realidad es construida socialmente" o "el ser humano es un sujeto activo" estamos dejando a un lado que esos son supuestos nuestros de aquello a lo que hacemos referencia, simplemente damos la impresión de que dichas declaraciones afirman un hecho "tal y como es" en una realidad externa a nosotros a la cual aprehendemos (ontología moderna). Caso distinto sería si dijésemos por ejemplo: "la realidad la asumimos como construida socialmente" o "el ser humano lo entendemos como un sujeto activo" para enfatizar con ello que, además de suponer tales afirmaciones, no entendemos nuestras afirmaciones como "absolutos" o "esencias" que existen al margen de nuestra actividad comprensiva. Con esto no se 
trata simplemente de sustituir un verbo por otro, o expresiones por otras, lo que quiero destacar es que cualquier expresión que usemos la revisemos críticamente -haciendo las salvedades pertinentes a que hubiese lugar- para despojarla de las concepciones ontológicas y epistemológicas que decimos rechazar.

\section{Referencias}

Fernández Christlieb, Pablo. (1987). Consideraciones teórico-metodológicas sobre la psicología política. En Maritza Montero (Coord.), Psicología Política Latinoamericana (pp. 75-99). Caracas: Panapo.

Fernández Christlieb, Pablo. (1994). La lógica epistémica de la invención de la realidad. En Fascículo de AVEPSO 6, 19-35.

González Rey, Fernando. (1994). Personalidad, Sujeto y Psicología Social. En Maritza Montero (Coord.), Construcción y crítica de la psicología social (pp. 149-176). Barcelona, España: Anthropos/U.C.V.

González Rey, Fernando. (2002). La subjetividad: Su significación para la ciencia psicológica. En Odair Furtado y Fernando González Rey (Org.), Por uma epistemologia da subjetividade: Um debate entre a teoria sócio-histórica e a teoria das representações sociais (pp. 17-42). São Paulo: Casa do Psicólogo.

Guba, Egon. (1990). The alternative paradigm dialog. En Egon Guba (Ed.), The paradigm dialog (pp. 17-27). Thousand Oaks: SAGE.

Ibáñez, Tomás. (1996). Fluctuaciones conceptuales en torno a la postmodernidad y la psicología. Caracas: Comisión de estudios de postgrado de la U.C.V.

Martínez, Miguel. (1996a). El paradigma emergente. Hacia una nueva teoría de la racionalidad científica. México: Trillas.

Martínez, Miguel. (1996b). Formas alternas del pensar científico. Revista Educación y Ciencias Humanas, Año IV (6), 31-54.

Mires, Fernando. (1996). La revolución que nadie soñó, o la otra postmodernidad. Caracas: Nueva Sociedad.

Montero, Maritza. (1994). Un paradigma para la psicología social. Reflexiones desde el quehacer en América Latina. En Maritza Montero (Coord.), Construcción y crítica de la psicología social (pp. 27-48). Barcelona, España: Anthropos/U.C.V.

Munné, Frederic. (1989). Entre el individuo y la sociedad. Barcelona, España: PPU.

Piaget, Jean. (1979). Tratado de lógica y conocimiento científico: Naturaleza y método de la epistemología. Buenos Aires: Paidós. 


\section{Formato de citación}

Ledezma, Nelson (2005). Modernidad y Psicología: una disyuntiva y una paradoja. Athenea Digital, 8. Disponible en http://antalya.uab.es/athenea/num8/Ledezma.pdf

Nelson Ledezma Venezolano, 27 años. Licenciado en Psicología (Universidad Central de Venezuela) con mención en Psicología Social. Egresado en Julio 2005, tesis con mención Publicación en psicología política. Facilitador de Aprendizaje-UCV en el semestre 2003-1. Ponente en el XXV Congreso de la Asociación Latinoamericana de Sociología (Brasil).

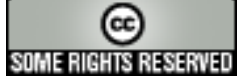

Este texto está protegido por una licencia $\underline{\text { Creative Commons. }}$

Usted es libre de copiar, distribuir y comunicar públicamente la obra bajo las siguientes condiciones:

Reconocimiento: Debe reconocer y citar al autor original.

No comercial. No puede utilizar esta obra para fines comerciales.

Sin obras derivadas. No se puede alterar, transformar, o generar una obra derivada a partir de esta obra.

\section{$\underline{\text { Resumen de licencia }}$}

$\underline{\text { Texto completo de la licencia }}$ 